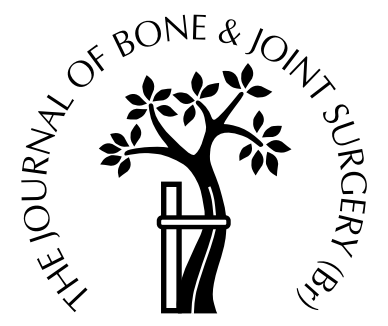

\title{
The effect of increased stress on the patellar tendon
}

\author{
H. Tohyama, K. Yasuda \\ From Hokkaido University School of Medicine, Sapporo, Japan
}

W e performed a biomechanical and histological study to clarify the effect of stress enhancement on the in situ frozen-thawed patellar tendon of the rabbit as a tendon autograft model. We used 48 Japanese White rabbits divided into three groups. In group 1, the patellar tendon underwent in situ freeze-thaw treatment with liquid nitrogen to kill intrinsic fibroblasts. In group 2, after similar treatment, the medial and lateral portions were resected so that the cross-sectional area was reduced by a third. In group 3 , after treatment, the cross-sectional area was reduced by a half. In groups 2 and 3 , the stress in the tendon was calculated theoretically to be $150 \%$ and $200 \%$ of the physiological stress during locomotion.

Eight rabbits in each group were killed at three and six weeks, respectively. At three weeks, the mean values for the tensile strength of groups 2 and 3 were $113.7 \%$ and $75.7 \%$ of that of group 1 , and at six weeks $101.2 \%$ and $57.4 \%$, respectively. The tensile strength in group 3 was significantly lower than that in groups 1 and 2 . The histological findings in group 2 were similar to those in group 1 , although an acellular area appeared to be wider in the core portion compared with group 1 at each period. In group 3 , the collagen bundles of the tendon were less organised than those of groups 1 and 2.

Our findings showed that stress enhancement affects the remodelling of the frozen-thawed patellar tendon and that excessively high stress reduces the mechanical properties of the tendon. This indicates that high stress on the patellar tendon autograft should be avoided during ligament reconstruction.

J Bone Joint Surg [Br] 2002;84-B:440-6.

Received 7 March 2000; Accepted after revision 17 August 2001

H. Tohyama, MD, PhD, Associate Professor

K. Yasuda, MD, PhD, Professor

Division of Medical Bioengineering and Sports Medicine, Department of Advanced Surgery, Hokkaido University School of Medicine, Kita-15 Nishi-7, Sapporo 060-8638, Japan.

Correspondence should be sent to Dr H. Tohyama.

(C)2002 British Editorial Society of Bone and Joint Surgery 0301-620X/02/311107\$2.00
The patellar tendon is commonly used as autograft in the reconstruction of ligaments. A number of histological and biochemical studies have shown that necrosis of fibroblasts in the transplanted tendon occurs sequentially during the early phase after such reconstruction. ${ }^{1-4}$ The graft is initially enveloped by vascular synovial tissue which initiates a revascularisation response that is accompanied by cellular proliferation. This revascularisation may take as long as 20 weeks to complete. Biomechanical studies have shown that the mechanical properties of the graft are extremely low at one year, compared with those of the original tendon, although they increase with time. ${ }^{3,5,6}$ Thus, there is an obvious discrepancy between the histological maturation and the mechanical restoration. In order to explain this discrepancy, we have suggested that various factors may affect the mechanical properties of the graft during the remodelling process after transplantation. ${ }^{7,8}$ We have reported that stress deprivation significantly reduces the biomechanical and ultrastructural properties of the graft, depending on the degree of shielded stress. ${ }^{9-12}$

There have been few studies on the clarification of the effect of stress enhancement on the patellar tendon autograft. Yoshiya et $\mathrm{al}^{13}$ studied the effect of the initial graft tension on the graft using reconstruction of the anterior cruciate ligament (ACL) in a canine model. They reported that the initial tension of the graft had no significant effect on its mechanical properties, and a graft which was initially fixed at a tension of $39 \mathrm{~N}$ had poor vascularity and greater disorganisation of collagen fibres compared with one fixed at $1 \mathrm{~N}$. In their study, however, apart from the initial graft tension many intra- and postoperative factors may have affected the biomechanical results because they performed the reconstruction using a free patellar tendon graft in a canine model. Thus, little remains known about the effect of stress enhancement on the patellar tendon autograft and to clarify this it is necessary to isolate it from the effects of the other factors.

Intrinsic necrosis of fibroblasts is the most essential change in the autograft used for ligament reconstruction. $^{-4,14}$ We have therefore established a model of a patellar tendon autograft by necrotising fibroblasts in the tendon using in situ freeze-thaw treatment. ${ }^{9-12,15}$ Hayashi and Yamamoto ${ }^{16,17}$ developed the marginal resection technique for the patellar tendon to increase the stress in the 
tendon. $^{16,17}$ Using these techniques, we have isolated the effect of stress enhancement from that of other factors and attempted to clarify biomechanically and histologically this effect on the in situ frozen-thawed patellar tendon.

\section{Materials and Methods}

We used 48 mature female Japanese White rabbits weighing $3.4 \pm 0.2 \mathrm{~kg}$ (mean $\pm \mathrm{SD}$ ) and aged 20 weeks or older. The experiment was carried out under the Rules and Regulations of the Animal Care and Use Committee of Hokkaido University School of Medicine. There were 16 animals in each of three groups. In group 1, the right patellar tendon underwent in situ freeze-thaw treatment with liquid nitrogen to kill intrinsic fibroblasts. ${ }^{12,16-19}$ In group 2, the same treatment was carried out and the medial and lateral sixths were then resected so that the cross-sectional area of the remaining tendon was reduced by a third in order to enhance the stress $^{16,17}$ (Fig. 1). In group 3, the same treatment was undertaken followed by resection of the medial and lateral quarters so that the remaining crosssectional area was halved (Fig. 1). After operation the animals were allowed unrestricted activity in the cage. They were able to walk on all four limbs four or five days after surgery without impairment.

Eight rabbits in each group were killed using an overdose of barbital sodium under intravenous pentobarbital anaesthesia at three and six weeks after surgery. Based on power analysis with our pooled data of normal rabbit patellar tendons, five from each group of eight were used for biomechanical evaluation at each period. The analysis had indicated that statistical comparison between the five animals and normal values had a $20 \%$ probability of a typeII error $(\alpha$ power $>80 \%)$, when the difference in the tensile
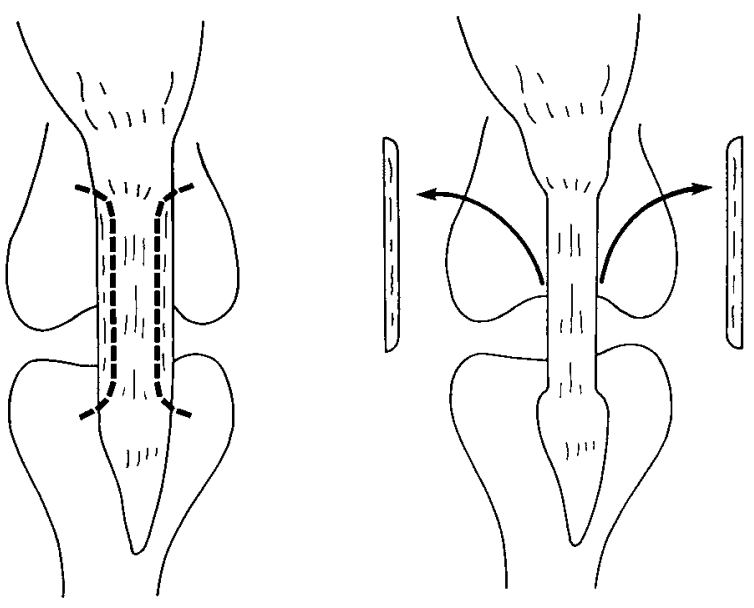

Fig. 1

Diagram showing the stress-enhancement treatment for the patellar tendon. The medial and lateral margins of the tendon are resected along the longitudinal axis so that the cross-sectional area of the remaining tendon becomes $66 \%$ to $67 \%$ and $49 \%$ to $51 \%$ of the original area in groups 2 and 3, respectively, in order to enhance the stress. strength from the normal value was less than $10 \mathrm{MPa}$. Three animals were used for histological examination at each period in each group. In addition, eight patella-patellar tendon-tibia complexes were randomly harvested from the left knees of all rabbits to obtain normal control data.

Operative procedure. All animals were operated on using sterile techniques under intravenous pentobarbital anaesthesia $(0.05 \mathrm{mg} / \mathrm{kg})$. The subcutaneous retinacula were incised longitudinally along the patellar tendon after the anterior aspect of the right knee had been exposed via a straight skin incision. The posterior surface of the patellar tendon was separated from the infrapatellar fat pad. Care was taken not to injure the fibres of the tendon. In group 1 a silicone rubber sheet was inserted between the tendon and the fat pad to make a bath with the tendon inside it. This bath was then filled with liquid nitrogen. The tendon was frozen for one minute and then thawed by pouring physiological saline solution into the bath. In group 2, after the right patellar tendon had undergone the same freeze-thaw treatment, the cross-sectional area of the whole tendon was measured in situ using an area micrometer with an $8 \mathrm{~mm}$ wide slot under a compressive stress of $0.12 \mathrm{MPa}$. The area micrometer is described in detail under 'mechanical testing'. Measurement of the cross-sectional area was performed again after the lateral and medial sixths of the tendon had been resected. We used the cross-sectional area micrometer with a $6 \mathrm{~mm}$ wide slot for the narrowed patellar tendon in group 2. The medial and lateral edges of the tendon were resected until the cross-sectional area became $66 \%$ to $67 \%$ of the original cross-sectional area. Care was taken to avoid damaging the sites of insertion and the remaining tendon. Theoretically, $150 \%$ of the physiological stress was applied in group 2. Group 3 was treated in the same way as group 2 except that the cross-sectional area of the tendon was reduced by $49 \%$ to $51 \%$. Theoretically, $200 \%$ of the physiological stress was applied to the remaining tendon in group 3 . The ratio of the cross-sectional area of the remaining tendon to that of the original tendon was $66.9 \pm 1.5 \%$ and $50.1 \pm 0.3 \%$ in groups 2 and 3 , respectively. In each group, the fascia and skin were closed with interrupted monofilament nylon sutures.

Mechanical testing. The hind limbs were resected immediately after the death of the animal. They were wrapped in sheets of gauze soaked with physiological saline and stored in air-tight bags at $-32^{\circ} \mathrm{C}$ until mechanical testing. ${ }^{20}$ Before testing, each specimen was thawed overnight at $4^{\circ} \mathrm{C}$. The patella-patellar tendon-tibia complex was dissected from each limb. Care was taken to keep the patellar tendon moist with physiological saline at all times.

Using an area micrometer, we measured the cross-sectional area of each tendon at three different positions (the middle and $5 \mathrm{~mm}$ proximal and distal to the middle). The area micrometer has an $8 \mathrm{~mm}$ wide and $5 \mathrm{~mm}$ thick rectangular slot and a plunger which inserts into the slot. The tendon was placed in the slot, and the plunger was inserted and pressed against the tendon with a constant compressive 
stress of $0.12 \mathrm{MPa}$ applied for two minutes. ${ }^{18,21}$ This stress compressed the tendon to fill the slot while the thickness of the tendon was measured by the micrometer. The crosssectional area was calculated by multiplying the width of slot by the thickness. It was represented by the mean of three values obtained from the three different positions. The length of the tendon was defined as the distance from the distal end of the patellar attachment to the proximal end of the tibial attachment. This length was measured on the surface of the tendon by a digital vernier caliper, while the tendon was suspended with a $50 \mathrm{~g}$ calibration weight.

For evaluation of the mechanical properties of the tendon, we narrowed it in order to prevent failure at its sites of insertion during the tensile test, because the entire normal substance of the tendon was stronger than the bone at these sites. ${ }^{18}$ The medial and lateral thirds were removed using a specially designed cutter with two $15 \mathrm{~mm}$ long stainlesssteel razor blades, $3.5 \mathrm{~mm}$ apart. Subsequently, the crosssectional area of the remaining tendon was measured using an area micrometer with a $4 \mathrm{~mm}$ wide rectangular slot. The patella and the tibia were cast in aluminium pots using PMMA resin. A stain (Nigrosine) was used to draw two parallel lines transversely on the surface of the tendon for use as gauge-length markers in strain measurement. One line was drawn $4 \mathrm{~mm}$ distal to the inferior pole of the patella, the other $4 \mathrm{~mm}$ proximal to the tibial attachment of the tendon; the distance between the two lines was approximately $12 \mathrm{~mm}$. The bone-tendon preparation was mounted on a set of specially designed grips and attached to a tensile tester (PTM-250W; Orientec Co, Tokyo, Japan) with the tibia flexed at $45^{\circ}$. The test was documented by a video camera and a recorder for strain analysis using a dimension-analyser system ${ }^{18,22}$ which could convert the distance between stained lines on the video image into an output voltage. Thus, the strain in the midsubstance of the tendon could be determined during tensile loading, independent of elongation at the sites of insertion.

The specimen was immersed in physiological saline at $37^{\circ} \mathrm{C}$ during testing. After applying a preload of $0.5 \mathrm{~N}$ for ten minutes, it was subjected to ten loading-unloading cycles between elongation limits of $0 \mathrm{~mm}$ and $0.5 \mathrm{~mm}$ at a rate of $20 \mathrm{~mm} / \mathrm{min}$ and then stretched to the point of failure at the same rate. During tensile testing, the load and the displacement between the two markers with the video dimension-analyser system were recorded on a pen recorder (X-Y-T recorder 3023-23; Yokogawa Co, Tokyo, Japan). From the load-displacement relation, a stress-strain curve was obtained in which stress was calculated by dividing the tensile load by the cross-sectional area, and strain by dividing displacement by the initial gauge length. The elastic modulus, the tensile strength, and the strain at failure were then determined. ${ }^{18,22}$

Histological examination. The patella-patellar tendon-tibia complexes were harvested from the hind limbs immediately after the death of the animal and the surrounding tissues carefully removed. The specimens were sectioned along the longitudinal axis of the tendon. Each complex was then fixed in a $10 \%$ buffered formalin solution, decalcified, cast in a paraffin block, stained with haematoxylin and eosin and examined by light microscopy.

Statistical analysis. We used two-way analysis of variance (ANOVA) to assess the effects of treatment and time on the cross-sectional area, the length, the elastic modulus, the tensile strength and the strain at failure. Fisher's PLSD test was applied for post-hoc multiple comparisons. The limit of significance was set at $\mathrm{p}=0.05$.

\section{Results}

Tissue dimensions. Two-way ANOVA showed a significant difference in the cross-sectional area with respect to group and to time (among groups, $p=0.001$, power $(1-\beta)=$ 1.000 ; between time periods, $\mathrm{p}=0.001$, power $(1-\beta)=$ 0.985 ; interaction, $p=0.705$, power $(1-\beta)=0.099)$. The cross-sectional area at six weeks was significantly greater than that at three weeks $(p=0.001)$. The mean values for the area in group 2 were $68.3 \%$ and $67.3 \%$ of those of group 1 at three and six weeks, respectively, which was significant $(p=0.001)$. The mean values for the area in group 3 were $60.1 \%$ and $57.9 \%$ of those of group 1 at three and six weeks, respectively $(p=0.001)$ and were also significantly smaller than in group $2(\mathrm{p}=0.008)$. Regarding the length of the tendon, we failed to show a significant difference in the three groups or between three and six weeks (among groups, $\mathrm{p}=0.058$, power $(1-\beta)=0.552$; between time periods, $p=0.810$, power $(1-\beta)=0.056$; interaction, $p=0.502$, power $(1-\beta)=0.152)$ (Table I). The mean values for the length in group 2 were $96.1 \%$ and $100.5 \%$ of those of group 1 at three and six weeks, respectively, and those in group 3 were $102.4 \%$ and $111.6 \%$ of group 1 at three and six weeks, respectively.

Mechanical properties. All specimens failed between the gauge lines in the tendon substance. Figure 2 shows the stress-strain curves of the three groups at each period compared with the control curve. The curve of group $3 \mathrm{had}$ the smallest slope and the lowest peak.

At three weeks, the mean values of tensile strength for groups 2 and 3 were $113.7 \%$ and $75.7 \%$ of group 1 (Table

Table I. Mean ( \pm SD) cross-sectional area and length of the patellar tendon at three and six weeks compared with the control

\begin{tabular}{|c|c|c|c|}
\hline & $\begin{array}{l}3 \text { weeks } \\
(n=5)\end{array}$ & $\begin{array}{l}6 \text { weeks } \\
(\mathrm{n}=5)\end{array}$ & $\begin{array}{l}\text { Control } \\
(\mathbf{n}=5)\end{array}$ \\
\hline Cross-sectional area $\left(\mathrm{mm}^{2}\right)$ & & & $13.9+1.2$ \\
\hline Group 1 & $18.3 \pm 1.9$ & $21.7 \pm 2.3$ & \\
\hline Group $2 *$ & $12.5 \pm 0.2$ & $14.6 \pm 1.4$ & \\
\hline Group $3 * \dagger$ & $9.7 \pm 3.0$ & $12.5 \pm 2.1$ & \\
\hline Length (mm) & & & $20.1 \pm 2.0$ \\
\hline Group 1 & $20.6 \pm 0.9$ & $19.8 \pm 0.9$ & \\
\hline Group 2 & $19.8 \pm 0.9$ & $19.9 \pm 1.5$ & \\
\hline Group 3 & $21.1 \pm 2.0$ & $22.1 \pm 3.2$ & \\
\hline
\end{tabular}

* significantly different from group $1(\mathrm{p}<0.05)$

$\dagger$ significantly different from group $2(\mathrm{p}<0.05)$ 


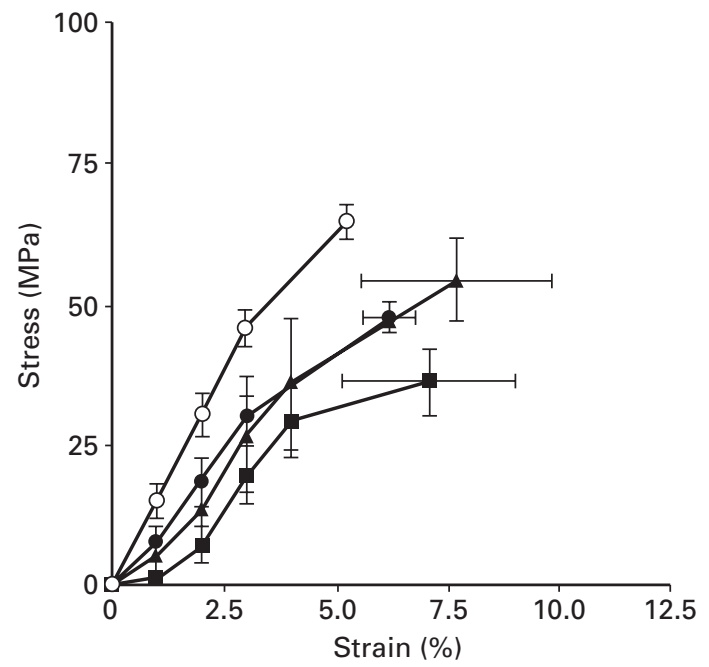

Fig. 2a

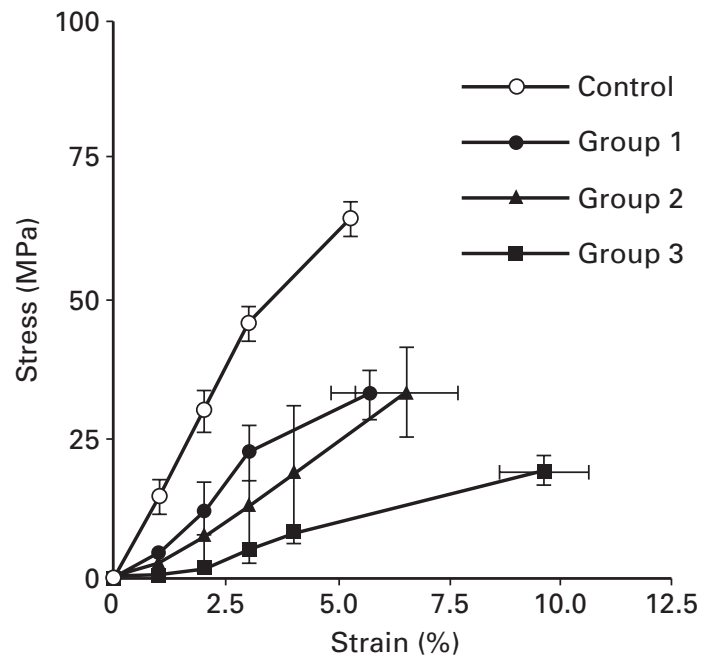

Fig. $2 b$

The mean ( \pm SEM) stress-strain curves of the three experimental groups $(n=5)$ and of the normal control tendon $(n=5)$ at a) three weeks and b) six weeks. The curves obtained from the three experimental groups are obviously different from the control curve. The curve for group 3 has the smallest slope and the lowest peak.

Table II. Mean ( \pm SD) values for the mechanical properties of the patellar tendon

\begin{tabular}{lrlr}
\hline & $\begin{array}{l}\text { 3 weeks } \\
(\mathbf{n = 5})\end{array}$ & $\begin{array}{l}\text { 6 weeks } \\
(\mathbf{n = 5})\end{array}$ & $\begin{array}{l}\text { Control } \\
(\mathbf{n = 5})\end{array}$ \\
\hline Tensile strength (MPa) & & & $64.2 \pm 6.8$ \\
$\quad$ Group 1 & $47.4 \pm 6.2$ & $32.9 \pm 9.8$ & \\
Group 2 & $53.9 \pm 16.2$ & $33.3 \pm 17.8$ & \\
$\quad$ Group 3 $\dagger$ & $35.9 \pm 13.3$ & $18.9 \pm 6.2$ & \\
Elastic modulus (MPa) & & & $1435 \pm 190$ \\
$\quad$ Group 1 & $1034 \pm 214$ & $632 \pm 112$ & \\
Group 2 & $1079 \pm 536$ & $607 \pm 202$ & \\
Group 3 & $985 \pm 412$ & $362 \pm 241$ & \\
Strain at failure (\%) & & & \\
Group 1 & $6.2 \pm 1.4$ & $5.7 \pm 1.9$ & \\
Group 2 & $7.7 \pm 4.7$ & $6.5 \pm 2.6$ & \\
Group 3 & $7.1 \pm 4.4$ & $9.6 \pm 2.2$ & \\
\hline
\end{tabular}

* significantly different from group $1(\mathrm{p}<0.05)$

$\dagger$ significantly different from group $2(\mathrm{p}<0.05)$

II) and at six weeks $101.2 \%$ and $57.4 \%$, respectively. Twoway ANOVA showed a significant difference with respect to group and time period (among groups, $\mathrm{p}=0.019$, power $(1-\beta)=0.735$; between time periods, $p=0.001$, power $(1-\beta)$ $=0.969$; interaction, $p=0.862$, power $(1-\beta)=0.070)$. The mean tensile strength of group 3 was significantly lower than that of group $1(\mathrm{p}=0.031)$ and group $2(\mathrm{p}=0.007)$. The difference in the mean tensile strength between group 3 and group 1 was $-11.7 \mathrm{MPa}$ (95\% confidence interval (CI) -26.7 to 3.6 MPa, $\mathrm{p}=0.117)$ and $-13.9 \mathrm{MPa}(95 \% \mathrm{CI}-25.9$ to-2.0 MPa, $\mathrm{p}=0.028$ ) at three and six weeks, respectively, while between group 2 and group 1 it was $6.5 \mathrm{MPa}(95 \% \mathrm{CI}$ -11.4 to $24.4 \mathrm{MPa}, \mathrm{p}=0.429)$ and $4.2 \mathrm{MPa}(95 \% \mathrm{CI}-20.5$ to 21.4 MPa, $\mathrm{p}=0.964)$, respectively. The mean tensile strength at six weeks was significantly lower than that at three weeks $(\mathrm{p}=0.019)$ (Table II).
We failed to show a significant difference in the elastic modulus among the groups $(p=0.243$, power $(1-\beta)=$ $0.178)$, but there was a significant difference between three and six weeks $(p=0.001$, power $(1-\beta)=0.969)$. We also failed to show a significant interaction effect between group and time $(p=0.862$, power $(1-\beta)=0.070)$. The mean values for the modulus of group 3 at three and six weeks were $57.3 \%$ and $59.6 \%$ of that of group 1, while of group 2 they were $104.4 \%$ and $96.0 \%$, respectively (Table II). The differences in the mean elastic modulus between groups 3 and 1 were $-49 \mathrm{MPa}(95 \% \mathrm{CI}-528$ to $430 \mathrm{MPa}, \mathrm{p}=0.819)$ and $-270 \mathrm{MPa}(95 \% \mathrm{CI}-543$ to $4 \mathrm{MPa}, \mathrm{p}=0.053)$ at three and six weeks, respectively, while between groups 2 and 1 the values were $44 \mathrm{MPa}(95 \% \mathrm{CI}-552$ to $639 \mathrm{MPa}$, $\mathrm{p}=0.870)$ and $-25 \mathrm{MPa}(95 \% \mathrm{CI}-263$ to $213 \mathrm{MPa}$, $\mathrm{p}=0.814)$. The modulus at six weeks was significantly lower than that at three weeks $(\mathrm{p}=0.001)$.

ANOVA failed to show any significant difference in strain at failure among groups or between time periods (among groups, $p=0.243$, power $(1-\beta)=0.278$; between time periods, $p=0.812$, power $(1-\beta)=0.056$; interaction, $\mathrm{p}=0.387$, power $(1-\beta)=0.195)($ Table II).

Histological findings. In group 1, some cells with an ovoid or spindle-shaped nucleus were observed in the posterior quarter of the tendon at three weeks, while none was seen in the core portion. Collagen bundles of group 1 were longitudinally aligned with a distinct crimped pattern (Fig. 3a). At six weeks, some cells with a rod-like nucleus occasionally appeared, while a number of cells with an ovoid or spindle-shaped nucleus were dispersed throughout the patellar tendon. The crimped pattern of the collagen bundles was less distinct compared with that seen at three weeks (Fig. 3b). In group 2, the histological findings of the collagen bundles and the shape of the cell nucleus were 


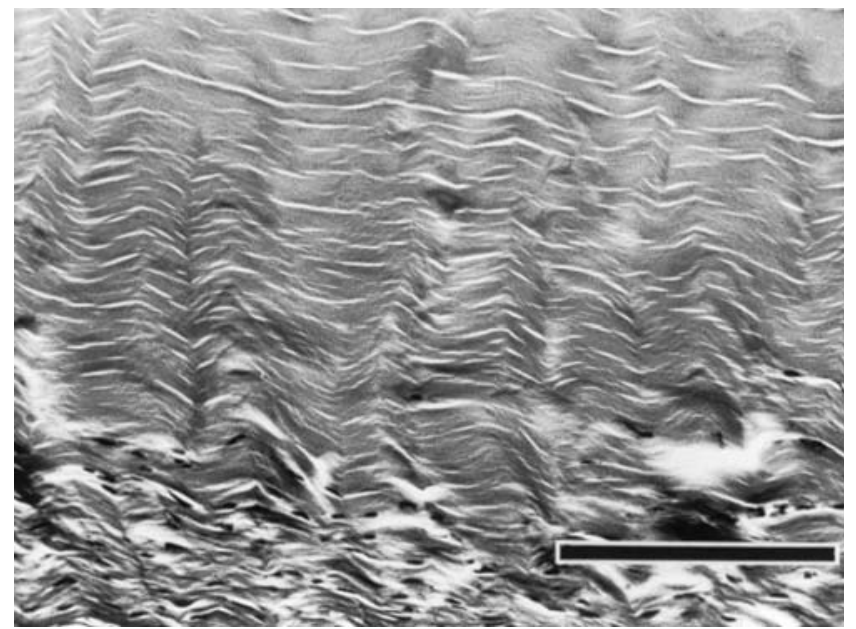

Fig. 3a

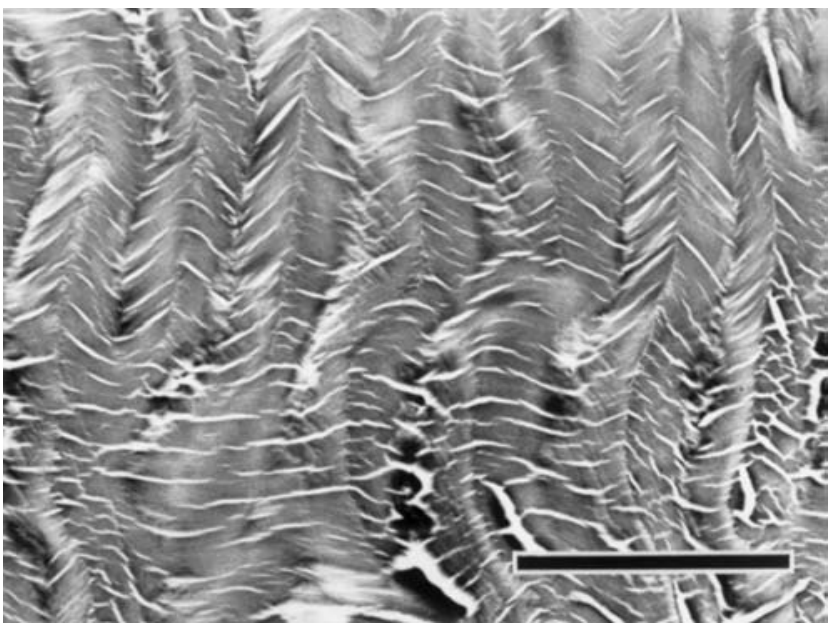

Fig. 3c

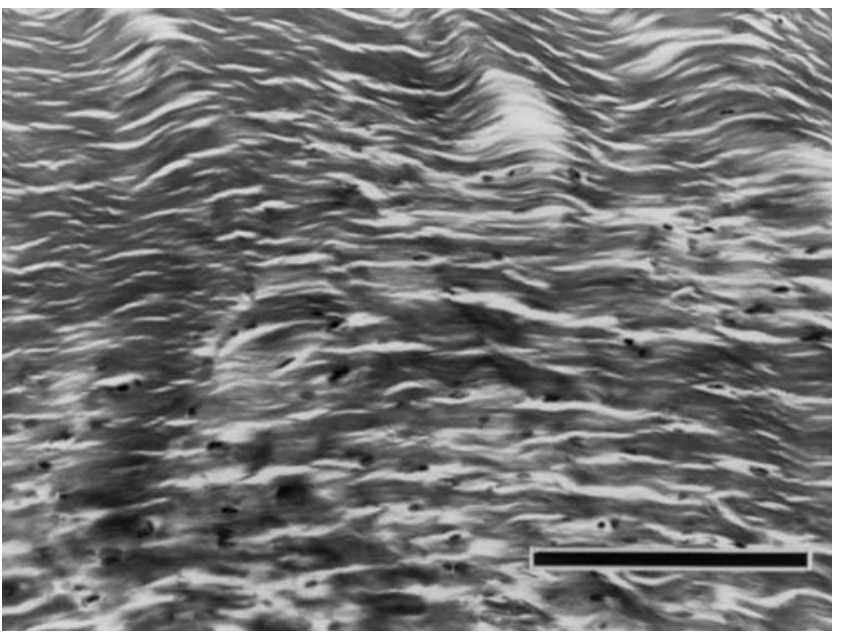

Fig. $3 e$

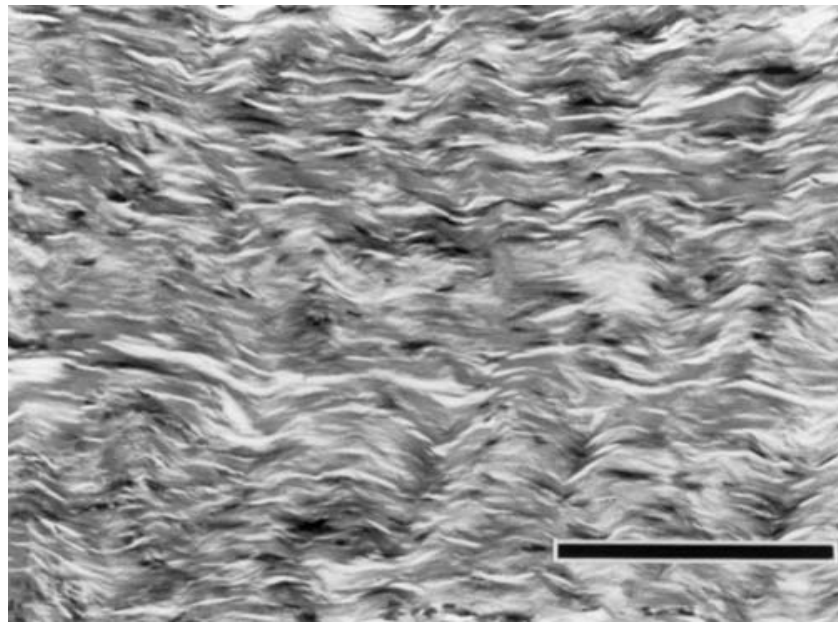

Fig. 3b

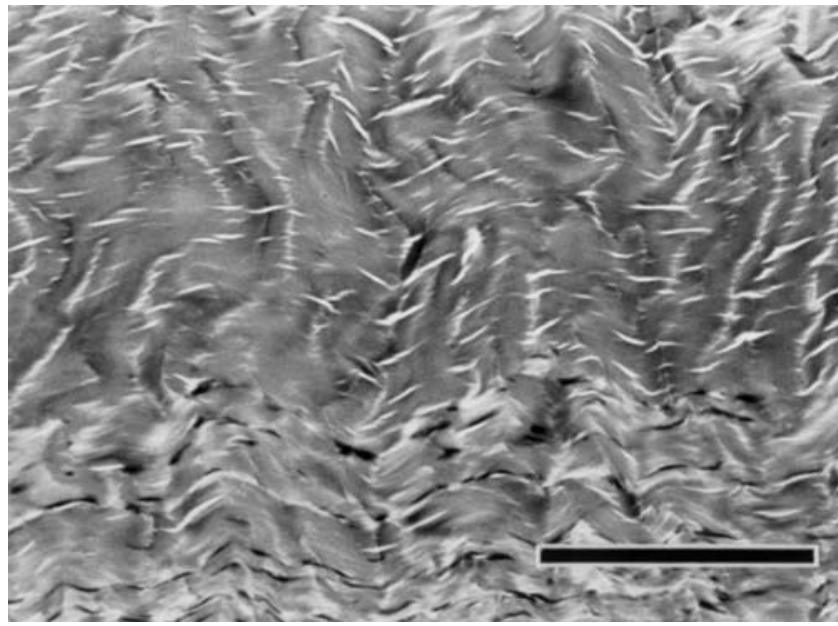

Fig. 3d

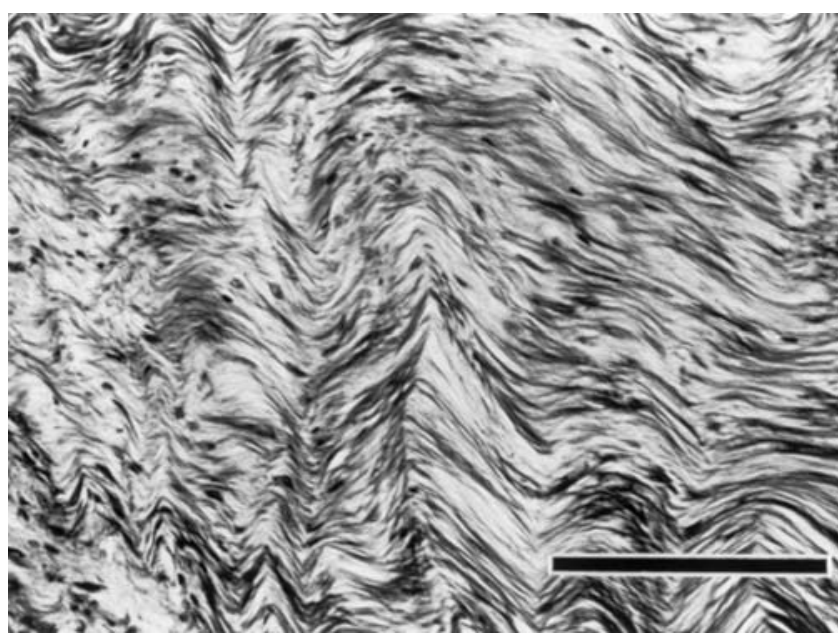

Fig. $3 f$

Photomicrographs of longitudinal sections of core portions of the patellar tendon. Figure $3 \mathrm{a}$ - Group 1 at three weeks. Some cells with an ovoid or spindle-shaped nucleus are present in the posterior quarter of the tendon (lower area). Figure $3 b-$ Group 1 at six weeks. There are some cells with a rod-like nucleus, while a number with an ovoid or spindle-shaped nucleus are dispersed. Figure $3 c-$ Group 2 at three weeks. The acellular area appears wider compared with group 1 at three weeks (Fig. 3a). Figure 3d - Group 2 at six weeks. The acellular area appears wider compared with group 1 at six weeks (Fig. 3b). Figure $3 \mathrm{e}-$ Group 3 at three weeks. There is fragmentation of the collagen bundles (lower area). Figure $3 \mathrm{f}-$ Group 3 at six weeks. The collagen bundles are less orientated compared with groups 1 and 2 (Figs $3 \mathrm{~b}$ and 3d) (haematoxylin and eosin, bar $=200 \mu \mathrm{m}$ ). 
similar to those of group 1, although an acellular area appeared to be wider in the core portion at each period (Figs 3c and 3d). In group 3, fragmentation of collagen bundles was observed in the tendon at three weeks. Some cells with an ovoid nucleus were seen in the posterior quarter of the tendon which had the same appearance as group 1, while cells with a spindle-shaped nucleus were less frequently observed (Fig. 3e). At six weeks, the collagen bundles of group 3 were less orientated compared with those of groups 1 and 2 (Fig. 3f). At each period, cells with an ovoid nucleus were often seen in disorientated collagen bundles, although no cells with a rod-like nucleus were observed in the tendons of group 3.

\section{Discussion}

In our study, doubling the physiological stress resulted in a deterioration of the tensile strength of the in situ frozenthawed patellar tendon and disorganisation of the collagen bundles. The increased stress decreased the mean elastic modulus of the tendon to $57 \%$ of that of the in situ frozenthawed tendon, although we failed to demonstrate a statistical significance. Our study has shown that stress enhancement which exceeds a certain level affects the remodelling of the in situ frozen-thawed patellar tendon.

This model has important advantages such as no disturbance to the sites of attachment of the tendon and no alteration of its mechanical environment. ${ }^{9-12,15}$

There are a few limitations in our study regarding the methodology. The first is that we used the in situ frozenthawed tendon as an autograft model. Because this is an extra-articular autograft model, the results cannot refer to the intra-articular autograft. The second limitation is that we could not quantify precisely the degree of the enhanced stress in the patellar tendon throughout the experimental period. Hayashi et al ${ }^{16,17}$ measured the in vivo tensile load of the rabbit patellar tendon which had been narrowed by the same method as that used in our study using a buckle transducer. They showed that there were no significant differences in the peak load between the narrowed and normal patellar tendons. This strongly suggests that the stress in the narrowed patellar tendon is enhanced. If the physiological load is applied to the narrowed tendons during locomotion, the stress value is calculated theoretically to be $150 \%$ and $200 \%$ of the physiological level in groups 2 and 3, respectively, during the early phase after surgery. Although the cross-sectional area of the remaining tendon increased with the passage of time, that in groups 2 and 3 remained $67.3 \%$ and $57.6 \%$ of that in group 1 at six weeks, respectively. Therefore we can calculate theoretically that the stress value in groups 2 and 3 at six weeks is $149 \%$ and $174 \%$ of that in group 1, respectively. The third limitation of our study is that we resected the medial and lateral margins of the tendon in order to reduce the cross-sectional area in groups 2 and 3 . It is possible that this surgical invasion may affect the tendon although care was taken to avoid damage to the sites of insertion and the remaining tendon. For the tendon in group 2, however, compared with group 1, we did not find detrimental effects of this procedure on the mechanical properties. We believe therefore that the effect of the surgical invasion was negligible.

Two mechanisms are possible to explain the detrimental effects of excessive stress enhancement on the mechanical properties of the frozen-thawed tendon. The first is that excessive stress enhancement may cause deterioration of the extracellular matrix in the tendon, specifically fatigue failure of collagen fibres. The second is that it may affect extrinsic cells which infiltrate the tendon after the intrinsic fibroblast necrosis, and that biological activity of the extrinsic cells may reduce the mechanical properties of the tendon. Hannafin et $\mathrm{al}^{19}$ studied the effect of tensile load on the canine flexor tendon using the in vitro tissue explant system. They reported that the application of a $1 \mathrm{~N}$ tensile load resulted in fibroblast necrosis and loss of the crimped pattern of the collagen, although the application of a $0.5 \mathrm{~N}$ tensile load did not affect the tendon. These facts imply that excessive stress directly damages the structure of the collagen of the tendon and they support the first potential mechanism. Many in vitro studies using cultured cells have shown that stress generally stimulates collagen synthesis of fibroblasts, osteoblasts and endothelial cells. ${ }^{23-25}$ These studies do not support the second mechanism. In order to clarify the mechanism of the detrimental effects of excessive stress enhancement on the frozen-thawed patellar tendon, in future studies they should be isolated from those on extrinsic cells.

Our histological findings indicate that moderate stress enhancement slightly delayed the infiltration of extrinsic cells from surrounding tissues into the tendon. Yoshiya et $\mathrm{al}^{13}$ showed that a patellar graft initially fixed at a tension of $39 \mathrm{~N}$ has poor vascularity compared with that fixed at $1 \mathrm{~N}$. Such poor vascularity induced by high stress may delay the infiltration of extrinsic cells into the tendon after intrinsic fibroblast necrosis.

It is important to compare the effect of stress enhancement to that of stress deprivation on the frozen-thawed patellar tendon, when we consider the effect of the mechanical environment on the graft. We have previously reported the effect of stress deprivation using the frozenthawed patellar tendon which was also used in this study. ${ }^{9,10}$ Complete stress-shielding decreases the tensile strength of the frozen-thawed patellar tendon to $17 \%$ and $28 \%$ of that of the physiologically stressed tendon at three and six weeks, respectively. The present study showed that excessive stress enhancement decreased the tensile strength of the frozen-thawed patellar tendon to $76 \%$ and $57 \%$ of that of the physiologically stressed tendon at three and six weeks, respectively. Thus, we find that excessive stress enhancement decreased the mechanical properties of the frozen-thawed patellar tendon more slowly than excessive stress deprivation. We consider that the mechanism of the deterioration of the frozen-thawed patellar 
tendon may be different in stress enhancement and deprivation.

We also compared the effects of stress enhancement on the extra-articular autograft model with those on the intraarticular model. Katsuragi et $\mathrm{al}^{26}$ evaluated the effects of stress enhancement on the mechanical properties of the frozen-thawed anterior cruciate ligament using a canine model. They reported that excessive stress enhancement did not affect the mechanical properties of the frozen-thawed ACL at six weeks, but that it significantly decreased them at 12 weeks. In addition, they also stated that excessive stress enhancement did not affect the cross-sectional area of the frozen-thawed ligament until 12 weeks. These findings are similar to those obtained in our study, although significant differences appear earlier in the extra-articular than in the intra-articular model. The similarity of the findings supports the main result of our study that excessive stress enhancement significantly decreases the mechanical properties of the frozen-thawed tissues as autograft models.

This study was supported by the Grants for General Scientific Research (\#10558124, \#12470299, \#12671389 and \#13671480) from the Ministry of Education, Science and Culture in Japan.

No benefits in any form have been received or will be received from a commercial party related directly or indirectly to the subject of this article.

\section{References}

1. Amiel D, Kleiner JB, Roux RD, Harwood FL, Akeson WH. The phenomenon of 'ligamentization': anterior cruciate ligament reconstruction with autogenous patellar tendon. J Orthop Res 1986;4:162-72

2. Arncoczky SP, Tarvin GB, Marshall JL. ACL replacement using patellar tendons. J Bone Joint Surg [Am] 1982;64-A:217-24.

3. Clancy WG, Narechania RG, Rosenberg TD, et al. Anterior and posterior cruciate ligament reconstruction in Rhesus monkeys. J Bone Joint Surg [Am] 1981;63-A:1270-84.

4. Kleiner JB, Amiel D, Harwood FL, Akeson WH. Early histologic, metabolic and vascular assessment of anterior cruciate ligament autografts. J Orthop Res 1989;7:235-42.

5. Ballock RT, Woo SL-Y, Lyon RM, Hollis JM, Akeson WH. Use of patellar tendon autograft for anterior cruciate ligament reconstruction in the rabbit: a long term histologic and biomechanical study. J Orthop Res 1989;7:474-85.

6. Butler DL, Grood ES, Noyes FR, et al. Mechanical properties of primate vascularised vs nonvascularised patellar tendon grafts: changes over time. J Orthop Res 1989;7:68-79.

7. Tohyama H, Yasuda K. Significance of graft tension in anterior cruciate ligament reconstruction: basic background and clinical outcome. Knee Surg Sports Traumatol Arthrosc 1998;6Suppl 1:30-7.
8. Yasuda K, Hayashi K. Remodeling of tendon autograft in ligament reconstruction. In: Hayashi K, Kamiya A, Ono K, eds. Biomechanics: functional adaptation and remodelling. Tokyo: Springer-Verlag, 1996:213-50.

9. Majima T, Yasuda K, Yamamoto N, Kaneda K, Hayashi $K$. Deterioration of mechanical properties of the autograft in controlled stress-shielded augmentation procedures: an experimental study with rabbit patellar tendon. Am J Sports Med 1994;22:821-9.

10. Ohno K, Yasuda K, Yamamoto N, Kaneda K, Hayashi K. Effects of complete stress-shielding on the mechanical properties and histology of in situ frozen patellar tendon. J Orthop Res 1993;11:592-602.

11. Tohyama H, Ohno K, Yamamoto $\mathbf{N}$, et al. Stress-strain characteristics of in situ frozen and stress-shielded rabbit patellar tendon. Clin Biomech 1992;7:226-30.

12. Tsuchida T, Yasuda $K$, Kaneda $K$, et al. Effects of in situ freezing and stress shielding on the ultrastructure of rabbit patellar tendons. J Orthop Res 1997;15:904-10.

13. Yoshiya S, Andrish JT, Manley MT, Baver TW. Graft tension in anterior cruciate ligament reconstruction: an in vivo study in dogs. Am J Sports Med 1987;15:464-70.

14. Kleiner JB, Amiel D, Roux RD, et al. Origin of replacement cells for the anterior cruciate ligament autograft. J Orthop Res 1986:4:466-74.

15. Ishida H, Yasuda K, Hayashi K, Yamamoto N, Kaneda K. Effects of resumption of loading on stress-shielded autografts after augmentation procedures: an experimental study. Am J Sports Med 1996;24:510-7.

16. Hayashi K, Yamamoto N, Yasuda K. Response of knee joint tendons and ligaments to mechanical stress. In: Hayashi K, Kamiya A, Ono K, eds. Biomechanics. Functional adaptation and remodelling. Tokyo: Springer-Verlag, 1996:185-212.

17. Yamamoto N, Hayashi $K$, Hayashi F, Yasuda $K$, Kaneda $K$. Biomechanical studies of the rabbit patellar tendon after removal of its one-fourth or a half. J Biomech Eng 1999;121:323-9.

18. Yamamoto N, Hayashi K, Kuriyama H, et al. Mechanical properties of the rabbit patellar tendon. J Biomech Eng 1992;114:332-7.

19. Hannafin JA, Arnoczky SP, Torzilli PA. The effect of immobilization and tensile load on the material of flexor digitorum profundus tendons: an in vitro study. Trans Orthop Res Soc 1993;18:154.

20. Woo SL, Orlando CA, Camp JF, Akeson WH. Effects of postmortem storage by freezing on ligament tensile behaviour. J Biomech 1986;19:399-404.

21. Butler DL, Grood ES, Noyes FR, Zernicke RF, Brackett K. Effects of structure and strain measurement technique on the material properties of young human tendons and fascia. J Biomech 1984;17:579-96.

22. Woo SL, Gomez MA, Seguchi Y, Endo CM, Akeson WH. Measurement of mechanical properties of ligament substance from a boneligament-bone preparation. J Orthop Res 1983;1:22-9.

23. Buckley MJ, Banes AJ, Jordan RD. The effects of mechanical strain on osteoblasts in vitro. J Oral Maxillofac Surg 1990;48:276-82.

24. Sumpio BE, Banes AJ, Levin LG, Johnson G Jr. Mechanical stress stimulates aortic endothelial cells to proliferate. J Vasc Surg 1987;6:252-6.

25. Sutker BD, Lester GE, Banes AJ, Dahmers LE. Cyclic strain stimulates DNA and collagen synthesis in fibroblasts cultured from rat medial collateral ligaments. Trans Orthop Res Soc 1990;15:130.

26. Katsuragi R, Yasuda K, Tsujino J, Keira M, Kaneda K. The effect of nonphysiologically high initial tension on the mechanical properties of in situ frozen anterior cruciate ligament in a canine model. Am J Sports Med 2000;28:47-56. 